\title{
IDAHO NATIONAL LABORATORY TRANSPORTATION TASK REPORT ON ACHIEVING MODERATOR EXCLUSION AND SUPPORTING STANDARDIZED TRANSPORTATION
}

D. Keith Morton

Brett W. Carlsen

Halim Alsaed

September 2011

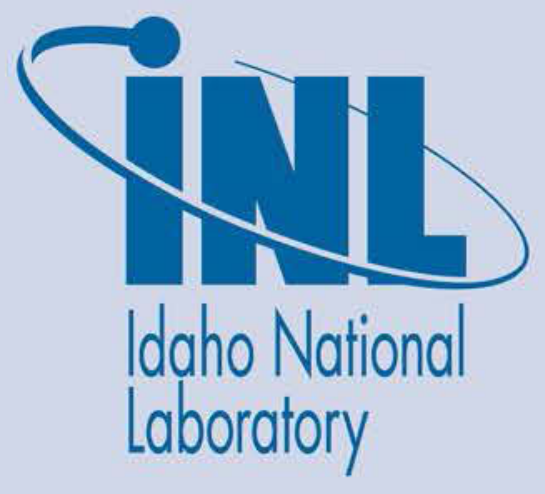

The INL is a U.S. Department of Energy National Laboratory operated by Battelle Energy Alliance 


\section{DISCLAIMER}

This information was prepared as an account of work sponsored by an agency of the U.S. Government. Neither the U.S. Government nor any agency thereof, nor any of their employees, makes any warranty, expressed or implied, or assumes any legal liability or responsibility for the accuracy, completeness, or usefulness, of any information, apparatus, product, or process disclosed, or represents that its use would not infringe privately owned rights. References herein to any specific commercial product, process, or service by trade name, trade mark, manufacturer, or otherwise, does not necessarily constitute or imply its endorsement, recommendation, or favoring by the U.S. Government or any agency thereof. The views and opinions of authors expressed herein do not necessarily state or reflect those of the U.S. Government or any agency thereof. 


\title{
IDAHO NATIONAL LABORATORY TRANSPORTATION TASK REPORT ON ACHIEVING MODERATOR EXCLUSION AND SUPPORTING STANDARDIZED TRANSPORTATION
}

\author{
D. Keith Morton \\ Brett W. Carlsen \\ and \\ Halim Alsaed
}

September 2011

Idaho National Laboratory

Idaho Falls, Idaho 83415

http://www.inl.gov

Prepared for the U.S. Department of Energy Office of Nuclear Energy Under DOE Idaho Operations Office

Contract DE-AC07-05ID14517 

Idaho National Laboratory

\section{IDAHO NATIONAL LABORATORY TRANSPORTATION TASK REPORT ON ACHIEVING MODERATOR EXCLUSION AND SUPPORTING STANDARDIZED TRANSPORTATION}

INL/EXT-11-22559

September 2011

Approved by:

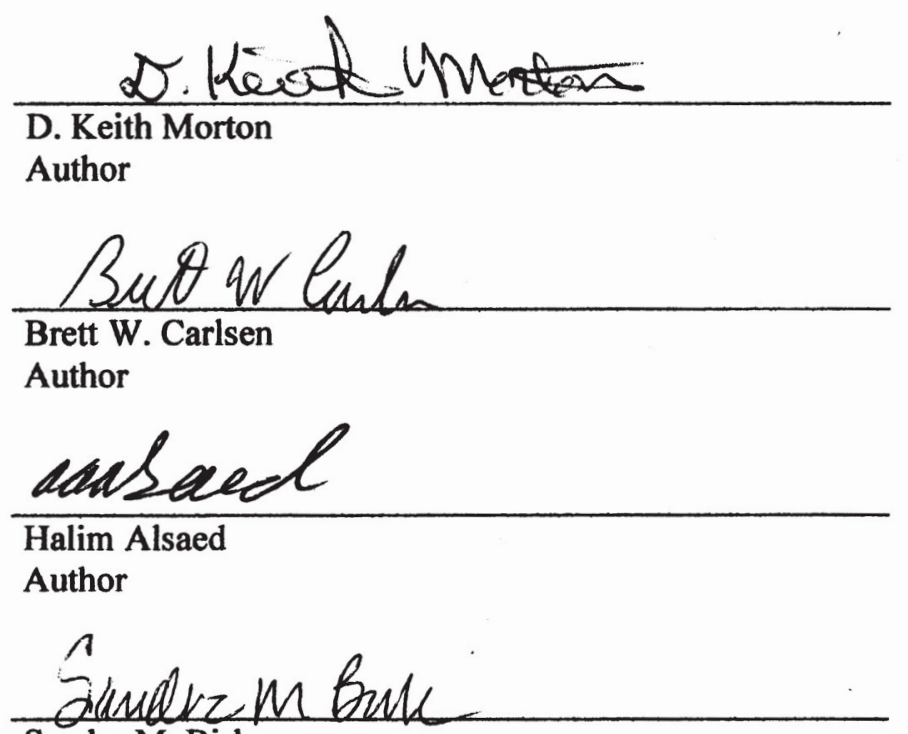
Sandra M. Birk

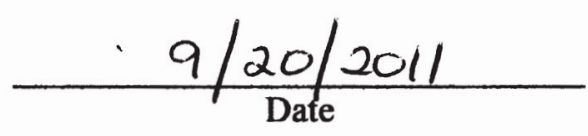

D. Keith Morton

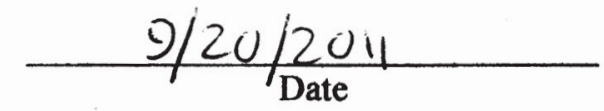

Nuclear Material Disposition \& Engineering Manager

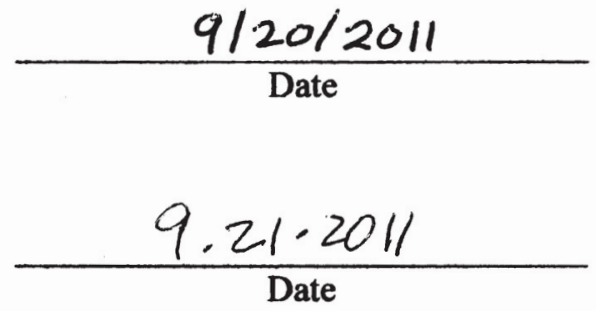




\begin{abstract}
Following the defunding of the Yucca Mountain Project, it is reasonable to assume that commercial used fuel will remain in storage for the foreseeable future. This report proposes supplementing the ongoing research and development work related to potential degradation of used fuel, baskets, poisons, and storage canisters during an extended period of storage with a parallel path. This parallel path can assure criticality safety during transportation by implementing a concept that achieves moderator exclusion (no in-leakage of moderator into the used fuel cavity). Using updated risk assessment insights for additional technical justification and relying upon a component inside of the transportation cask that provides a watertight function, a strong argument can be made that moderator intrusion is not credible and should not be a required assumption for criticality evaluations during normal conditions of transportation. A demonstration testing program supporting a detailed analytical effort as well as updated risk assessment insights can provide the basis for moderator exclusion during hypothetical accident conditions. This report also discusses how this engineered concept can support the goal of standardized transportation.
\end{abstract}




\section{ACKNOWLEDGEMENTS}

The authors would like to acknowledge the willingness of the following individuals to participate in discussions with the authors regarding the proposed concept presented in this report and the insightful review comments they provided on the initial draft of this report.

Mr. Chuck Temus

Mr. Brandon Thomas

Mr. Jim Hopf

Mr. Luis Hinojosa

Dr. Kalyan Niyogi

Mr. Charles Pennington

Mr. Bill Bracey 


\section{CONTENTS}

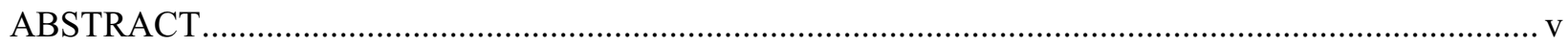

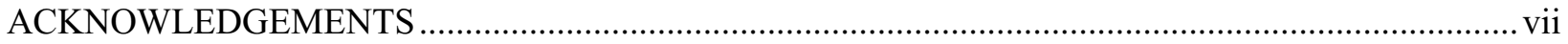

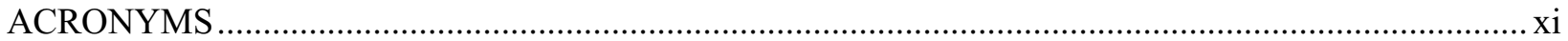

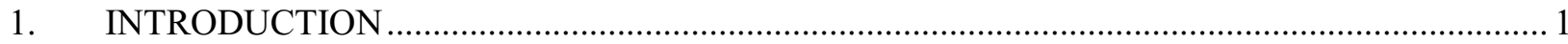

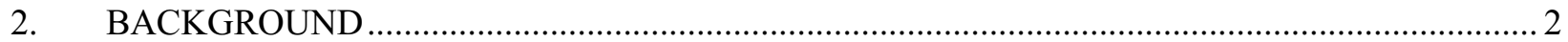

3. RECENT LICENSING EXPERIENCE WITH MODERATOR EXCLUSION ….......................... 3

4. AN APPROACH FOR ACHIEVING MODERATOR EXCLUSION ….................................... 5

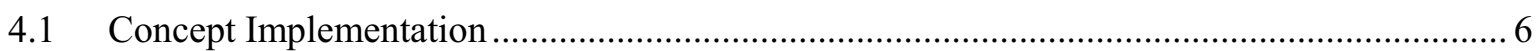

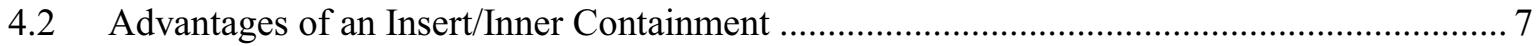

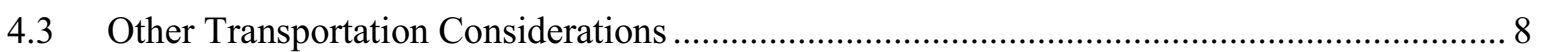

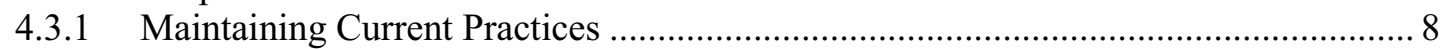

4.3.2 ASME BPV Code Support....................................................................... 9

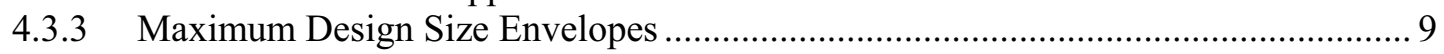

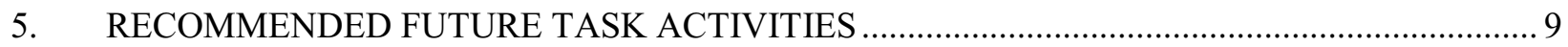

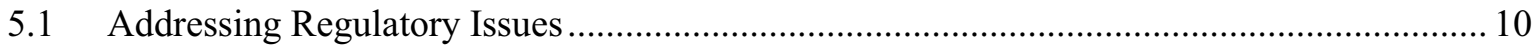

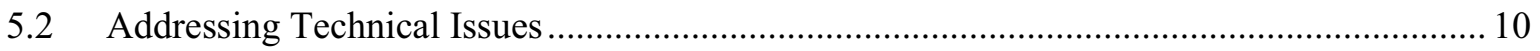

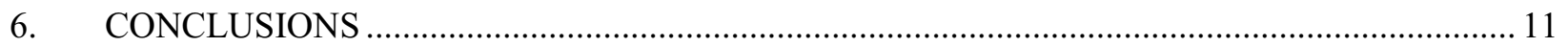

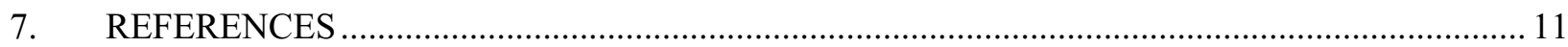

\section{FIGURES}

Figure 1. Proposed insert/inner containment concept. 


\section{ACRONYMS}

ACNW Advisory Committee on Nuclear Waste

ASME American Society of Mechanical Engineers

BPV Boiler and Pressure Vessel

CFR Code of Federal Regulations

DOE Department of Energy

FCRD Fuel Cycle Research and Development

GWd gigawatt-day

HI-STAR Holtec International Storage, Transport, and Repository

IAEA International Atomic Energy Agency

INL Idaho National Laboratory

ISG interim staff guidance

MTU metric tons (Tonnes) of uranium

NE DOE Office of Nuclear Energy

NRC Nuclear Regulatory Commission

NSNFP National Spent Nuclear Fuel Program

SFST Spent Fuel Storage and Transportation (a division under NRC's Office of Nuclear Material Safety and Safeguards) 


\section{IDAHO NATIONAL LABORATORY TRANSPORTATION TASK REPORT ON ACHIEVING MODERATOR EXCLUSION AND SUPPORTING STANDARDIZED TRANSPORTATION}

\section{INTRODUCTION}

Following the defunding of the Yucca Mountain Project, the Department of Energy (DOE) transitioned the former Office of Civilian Radioactive Waste Management responsibilities to the Office of Nuclear Energy (NE). One of the new programs created under NE is the Fuel Cycle Research and Development (FCRD) program. The mission of the FCRD program is to conduct research and development to help develop sustainable fuel cycles. Sustainable fuel cycle options improve uranium resource utilization, maximize energy generation, minimize waste generation, improve safety, and limit proliferation risk.

One of the technical areas under FCRD is Used Nuclear Fuel Disposition. The purpose of this effort is identified in its mission statement:

"The mission of the Used Nuclear Fuel Disposition technical area is to identify alternatives and conduct scientific research and technology development to enable storage, transportation, and disposal of used nuclear fuel and all radioactive wastes generated by existing and future nuclear fuel cycles. The challenge for Used Nuclear Fuel Disposition is the development of storage, transportation, and disposal systems resulting in near-zero radionuclide releases." a

In the absence of a currently identified disposition path for commercial used nuclear fuel, ${ }^{\mathrm{b}}$ it is reasonable to assume that used fuel will remain in storage for the foreseeable future. The U.S. Nuclear Regulatory Commission (NRC) recently revised 10 CFR Part 51.23 (Reference 2) as part of their waste confidence ruling, indicating that the Commission has made a generic determination that used fuel can be stored at least 60 years beyond the licensed life of operation for the reactor. Combining this with fuel stored during the operational life of the reactor (currently a maximum of 40 years with the initial operating license plus another 20 years with license renewal) yields a total of 120 years of safe wet and dry storage. The storage of used fuel may extend beyond this 120 -year period. Since the time interval for used fuel storage cannot be defined at this time, the term "extended storage" is used in this report to identify an unspecified period of used fuel storage after which transportation is to occur.

The Transportation and Storage Subcommittee reporting to the Blue Ribbon Commission on America's Nuclear Future was formed to examine issues related to the transportation and storage of used fuel and high-level radioactive waste in the United States. This Subcommittee issued its findings in a draft report ${ }^{c}$ that was organized around six key questions, two of which were:

\footnotetext{
${ }^{\text {a }}$ Department of Energy FY 2012 Congressional Budget Request, pages 79-80 (Reference 1).

b The term 'commercial used nuclear fuel' (hereafter referred to as 'used fuel') is used in this report to reflect that the material being transported may still be a resource to be recovered through processing, whereas 'spent fuel' may be considered to be more a waste. This 'used fuel' terminology (which includes the cladding) is not intended to conflict with the vast magnitude of literature, regulations, codes, and standards that have used the term 'spent fuel' or 'spent nuclear fuel'. 'Used fuel' is simply being used herein to indicate that a decision regarding its usefulness has not yet been determined. The term 'spent fuel' or 'spent nuclear fuel' will continue to be used in this report when used in a direct quotation, title, or the name of a specific component.

${ }^{c}$ Transportation and Storage Subcommittee Draft Report to the Full Blue Ribbon Commission on America's Nuclear Future, page 1 (Reference 3 ).
} 
"Are there technical or regulatory uncertainties related to the ability to store existing and future spent fuel and high-level waste safely and secure for an extended period of time (100 years or more) and then transport it safely and securely to another location?"

and

"What are the key issues that will affect the ability to transport spent fuel and high-level waste now and in the future at the scale that will eventually be required?"

The report provides additional insights that can be used to help answer these questions, discusses potential challenges to post-storage transportation, and proposes an engineered concept that can support the successful and safe transportation of commercial used fuel ${ }^{\mathrm{d}}$, regardless of its condition. The report's focus is on the benefits and plausibility of crediting moderator exclusion for ensuring criticality safety during transportation and how the proposed concept can also support the goal of standardized transportation.

\section{BACKGROUND}

The three basic safety objectives of the NRC regulations for transportation (Reference 4) of used fuel are to prevent criticality, prevent radiological release, and to minimize radiological exposure. A longstanding NRC requirement in the licensing of transportation systems is that the system must be designed to withstand the introduction of moderator (e.g., water) and still maintain criticality safety. If the used fuel, baskets, or poisons lose their structural integrity ${ }^{\mathrm{e}}$ and moderator enters the cavity where reconfigured fuel, baskets, or poisons are located, the ability to satisfy criticality criteria becomes difficult.

The NRC transportation requirement of 10 CFR 71.55(b) states:

"Except as provided in paragraph (c) or ( $g$ ) of this section, a package used for the shipment of fissile material must be so designed and constructed and its contents so limited that it would be subcritical if water were to leak into the containment system, or liquid contents were to leak out of the containment system so that, under the following conditions, maximum reactivity of the fissile material would be attained:

(1) The most reactive credible configuration consistent with the chemical and physical form of the material;

(2) Moderation by water to the most reactive credible extent; and

(3) Close full reflection of the containment system by water on all sides, or such greater reflection of the containment system as may additionally be provided by the surrounding material of the packaging."

10 CFR 71.55(b) applies to both normal and hypothetical accident conditions. ${ }^{\mathrm{f}}$ The application of 10 CFR 71.55(b) to normal conditions is considered by the NRC (Reference 6) and others (Reference 7) to be a required assumption. However, as can be seen, 10 CFR 71.55(b) has a stated exception, referring to 10 CFR 71.55(c), which states:

"The Commission may approve exceptions to the requirements of paragraph (b) of this section if the package incorporates special design features that ensure that no single packaging error

\footnotetext{
${ }^{\mathrm{d}}$ Although DOE is also responsible for DOE-owned used fuel and high-level radioactive waste, the main focus of this report is commercial used fuel.

${ }^{\mathrm{e}}$ High burnup fuel (greater than $45 \mathrm{GWd} / \mathrm{MTU}$ ) has the added concern of additional degradation by increasing the embrittlement of the cladding, regardless of the cladding material used.

${ }^{\mathrm{f}}$ It is recognized that 10 CFR 71.55(d) and (e) specifically address normal conditions and hypothetical accident conditions of transport, respectively and that SFST-ISG-19 (Reference 5) provides additional insights on testing requirements that can be used to achieve moderator exclusion for hypothetical accident conditions with high burnup fuel. Normal and hypothetical accident conditions are identified in 10 CFR Part 71.
} 
would permit leakage, and if appropriate measures are taken before each shipment to ensure that the containment system does not leak."

Existing regulatory requirements were initially written with the expectation of a relatively short period of wet and dry storage for the used fuel prior to transportation for processing or disposal. The regulatory requirements for storage (Reference 8), such as the use of an inert gas atmosphere under dry storage conditions, were written with the intention of minimizing degradation. However, after many decades of storage, reliance on the structural integrity of the used fuel, baskets, poisons, or even the storage canister itself to assure the transportation packaging remains subcritical may become a difficult objective. It is difficult to identify all credible degradation mechanisms and establish proper controls or mitigation processes, especially for components sealed inside of a storage canister. At present, insufficient data exist to make a conclusive determination of whether the structural integrity following extended storage will be sufficient to ensure proper geometric configuration control is maintained during normal and hypothetical accident conditions. Future examination techniques, test methods, or even repair processes may be developed to ensure the necessary structural integrity requirements but this could also be costly and/or unnecessarily increase radiation exposure to personnel.

Although the future regulatory framework is unknown and specific regulatory requirements cannot be anticipated, it is reasonable to assume that the three basic safety objectives of preventing radiological release, minimizing radiological exposure, and preventing criticality will remain. Of these objectives, meeting the two radiological safety requirements is expected to become less challenging after extended storage due to radiological decay of the used fuel. Thermal loads will also decrease. However, criticality safety may become more challenging as a result of degradation processes that may adversely affect the structural integrity of the used fuel, baskets, poisons, and the storage canister. It is reasonable to expect that some degradation will occur. Accurately quantifying this degradation and identifying the potential consequences may pose significant challenges. Therefore, conservatively assuming that the structural integrity cannot be assured provides a bounding scenario. The major concern then becomes how to demonstrate that the transportation packaging still satisfies criticality requirements.

Commercial nuclear fuel, whose enrichment is limited to $5 \mathrm{wt}$ \% U-235, cannot become critical in the absence of a moderator (Reference 9). Criticality-related questions associated with the structural integrity of used fuel, baskets, or poisons are not relevant if the introduction of moderator is prevented. Therefore, the most effective solution is not to allow moderator to enter the cavity where the used fuel is located. This approach is commonly called 'moderator exclusion'.

\section{RECENT LICENSING EXPERIENCE WITH MODERATOR EXCLUSION}

It is interesting to briefly note two recent NRC interactions [one by the National Spent Nuclear Fuel Program (NSNFP) and the other by Holtec International] that achieved certain levels of success regarding NRC acceptance of moderator exclusion.

\section{NSNFP}

In 2006, the NSNFP initiated a series of meetings with the NRC. The objective of these meetings was to obtain NRC acceptance of a transportation strategy that would allow crediting moderator exclusion as the basis for criticality safety for a variety of DOE-owned used fuels sealed within Standardized DOE Spent Nuclear Fuel Canisters (hereafter referred to as standardized canisters) and transported inside an NRC-approved transportation cask.

The basis for requesting moderator exclusion to be allowed was:

a. the need to package and eventually transport a broad range of used fuels under DOE's stewardship, many of which are not adequately characterized to provide material and chemical 
properties with sufficient certainty to support demonstration of criticality safety based on maintaining geometry under hypothetical accident conditions, and

b. the use of a robust, standardized canister that would provide an additional proven leaktight ${ }^{\mathrm{g}}$ barrier.

Fabrication and operational records necessary to reliably support burnup credit are not available for many DOE used fuels. For DOE to be able to take credit for used fuel burnup or structural integrity, a substantial characterization program would be necessary. The results from such a high-cost effort would (1) likely vary substantially because of the wide variety of DOE fuel designs and operating history, (2) result in additional and unnecessary personnel radiation exposure, and (3) result in additional radioactive waste generation. In addition to those downsides, considerable effort had already been made to develop both an empirical and analytical basis for assuring the standardized canister leaktightness.

The standardized canister would be part of a proposed transportation packaging system, consisting of a traditional transport cask containing multiple standardized canisters. The proposed system would thus have two containment boundaries; the standardized canister and the cask itself, each fully tested and demonstrated to remain leaktight under prescribed hypothetical accident conditions. DOE would thus rely on the engineered features of this standardized canister rather than on less certain used fuel characterization information. Using this approach, the safety margin formerly provided by an assumption of flooding is replaced by the added protection provided by an additional engineered barrier.

Criticality analyses, performed by the NSNFP, showed that a transportation cask containing standardized canisters loaded with used fuels in their as-loaded, undamaged configuration were subcritical, even with the transportation cask and all the standardized canisters flooded with moderator. Analyses also showed that the standardized canisters remained subcritical in a fully flooded transportation cask regardless of the extent of fuel damage as long as the standardized canisters themselves remained intact and excluded moderator. In summary, the proposed approach to transportation criticality safety was considered to be technically sound and to provide equivalent or improved levels of criticality safety when compared to existing practices.

Because allowing moderator exclusion was considered to be a departure from accepted practice, the NRC staff sought input from the NRC Commission on how to best proceed. A letter (Reference 6) was written by the staff that summarized existing NRC practice with respect to moderator exclusion. This letter outlined three options for proceeding with respect to requests for moderator exclusion and recommended an option that would codify the acceptable uses of moderator exclusion using the rulemaking process. The letter also noted presentations that the staff had made to the Advisory Committee on Nuclear Waste (ACNW). The ACNW (later renamed the Advisory Committee on Nuclear Waste and Materials) recommended that the NRC staff "use the existing rule at 10 CFR 71.55(c) to evaluate submittals from applicants seeking to apply moderator exclusion provisions of the rule" and gain more experience before making a decision about rulemaking. The ACNW also recommended that the NRC guidance be made risk-informed and include consideration of both moderator exclusion and burnup credit (Reference 11).

The NRC Commission disapproved the staff's recommendation (Reference 12) and, consistent with the ACNW recommendation, directed the staff to consider moderator exclusion on a case-by-case basis and continue to gain experience through processing of applicants' requests for moderator exclusion. The Commission's decision also encouraged the staff to focus efforts on using burnup credit and other means to provide a more realistic description of the used fuel composition as a means to allow more used fuel assemblies in a cask without creating a criticality event. Two of the three commissioners voting commented that they concurred with the ACNW recommendation.

${ }^{\mathrm{g}}$ ANSI N14.5 leaktight criterion is defined as a leak rate not greater than $10^{-7} \mathrm{ref} \mathrm{cc/sec}$ (Reference 10). 
After several meetings between NSNFP and NRC staff regarding the need and technical justification for moderator exclusion (including NRC staff visits to the Idaho National Laboratory (INL) to see standardized canister drop test specimens), a tentative agreement was reached regarding the form and content of a topical report to be submitted for NRC review and approval. The topical report would serve as the basis for future transportation vendors wishing to rely on moderator exclusion when transporting standardized canisters containing used fuel.

The NSNFP elected not to continue its pursuit of moderator exclusion in 2008 due to budget priorities and the subsequent defunding of the Yucca Mountain repository license application.

\section{Holtec International}

Holtec International, during this same timeframe, continued with their HI-STAR 180 application efforts. The HI-STAR 180 transportation cask is a metal cask with a Metamic-HT (metal matrix composite of aluminum and boron carbide) fuel basket. As described in the Safety Evaluation Report (SER) for HI-STAR 180 (Reference 13), "the package design includes two closure lids with each lid being individually designated as the containment boundary. Both the inner and outer lid feature two concentric annular metallic seals each, thus providing a total of four independent barriers against leakage." The HI-STAR 180 application did not pursue a moderator exclusion exemption per $10 \mathrm{CFR}$ 71.55(c), but rather applied the guidance in SFST-ISG-19 for demonstrating subcriticality for certain hypothetical accident conditions. The HI-STAR 180 SER states, "The applicant did not attempt to demonstrate that all possible reconfigurations were subcritical. However, criticality analyses for a limited number of fuel reconfigurations were performed by the applicant for a fully flooded package as defensein-depth. The applicant demonstrated that even under damaged fuel condition (and resulting fuel reconfiguration), no significant increase in reactivity occurred compared to intact fuel". To date, the HISTAR 180 transportation cask is the only transportation cask that has been granted a Certificate of Compliance by the NRC to transport used nuclear fuel on the basis of moderator exclusion for hypothetical accident conditions.

\section{Summary}

The NRC staff has indeed been gaining more experience through processing applicant's requests for moderator exclusion. Applicants have added another barrier, either incorporating the use of robust canisters inside of a transportation cask or relying upon a dual lid design with multiple seals. With these changes and more, moderator exclusion (at least for hypothetical accident conditions) is becoming a more acceptable option. A demonstration testing program supporting a detailed analytical effort can provide the basis for moderator exclusion during hypothetical accident conditions. These two examples indicate that there are options under which the NRC is willing to grant moderator exclusion associated with hypothetical accident conditions. Another positive step forward is to identify a process by which moderator exclusion can be granted for normal conditions of transport.

\section{AN APPROACH FOR ACHIEVING MODERATOR EXCLUSION}

This report proposes supplementing the ongoing research and development work related to understanding and managing the potential degradation of used fuel, baskets, poisons, and storage canisters with a parallel path that can assure criticality safety during transportation by relying on an engineered concept achievable with current technology.

A basic principle of defense-in-depth is the use of multiple barriers. Current international transportation safety standards (Reference 14) do not require the assumption of moderator leakage past multiple barriers (not less than two), when each barrier can be demonstrated to remain watertight under prescribed normal and accident condition tests and each packaging (before each shipment) is tested to demonstrate the closure. A separate and distinct component inside of a transportation cask and capable of 
performing the watertight function for moderator exclusion is believed to satisfy the conditions of 10 CFR 71.55(c). This special design inner component can ensure that no single packaging error would permit inleakage of moderator into the used fuel cavity. In addition, this component can be physically leak tested to demonstrate its capacity to be watertight. Combining the use of this watertight inner component with an updated probabilistic risk assessment that also reflects the use of the inner component is believed to provide the strongest justification that moderator intrusion is not credible during normal condition evaluations. With respect to hypothetical accident conditions, the same basic approach is recommended.

The NRC staff already acknowledges the low probability of transportation accident events (References 15 and 16) and the even lower probability of moderator intrusion associated with those accident events (Reference 17) based on probabilistic risk assessments. The existence of the inner component should lower those probabilities even more. In addition, a demonstration testing program (similar to that discussed in SFST-ISG-19) is recommended to support the analytical evaluations necessary to show the watertight condition is maintained during and after the hypothetical accident loadings.

\subsection{Concept Implementation}

Following a graded approach, an evaluation is made prior to any transportation effort regarding the condition and functional integrity of the used fuel, baskets, and poisons that support criticality safety, directing whether moderator exclusion is necessary or not. If moderator exclusion is not needed, the storage canister can be transported inside of the transportation cask as is. If moderator exclusion is necessary, following the multiple barrier concept, then a component is needed to provide the watertight function. That component could be either the storage canister or a separate additional inner containment that can completely enclose the storage canister. A non-degraded storage canister could provide the watertight function, although demonstrating that function just before transport could prove difficult after extended storage. For example, storage canisters are leak tested after loading so part of the new evaluation would be to determine if that initial leak test is still applicable. When the storage canister cannot provide the necessary watertight function (or if it has been determined that it is not worth the effort to make such an evaluation), a separate inner containment can be used to achieve moderator exclusion. Although a separate inner containment could be implemented for a transportation effort at any time, the potential to need an inner containment for transportation increases as the storage period is extended, perhaps many decades after initial storage canister loading.

Placing the storage canister into the transportation cask by itself could be problematic. The storage canister could experience excessive gaps within a transportation cask not custom built for that specific canister and could 'rattle around' inside of the cask during transportation. A reusable cask insert that adapts to the geometry of the storage canister could be used to provide better support and protection for the canister during transportation. Few transportation packagings currently exist (deployed and in use) worldwide that can be used to ship a commercial used fuel dry storage canister. However, DOE could effectively move forward by building a fleet of standardized transportation packagings that can accept a range of existing storage canisters. This would greatly simplify scheduling the use of transportation packagings. The key is to design reusable inserts that adapt the standardized transportation cask to each unique storage canister design. The insert can easily become an inner containment providing a watertight function simply by affixing a sealable lid. The proposed concept is therefore capable of meeting standardization goals and achieving moderator exclusion needs.

Figure 1 provides a very basic illustration of this insert/inner containment concept. No design details are provided since this is only a conceptual proposal. Multiple analytical evaluations and cost studies would be needed to fully evaluate the many aspects of this concept. Yet, the concept being proposed illustrates that DOE can proceed with extended storage and have confidence that transportation solutions are available and can be reasonably implemented. 


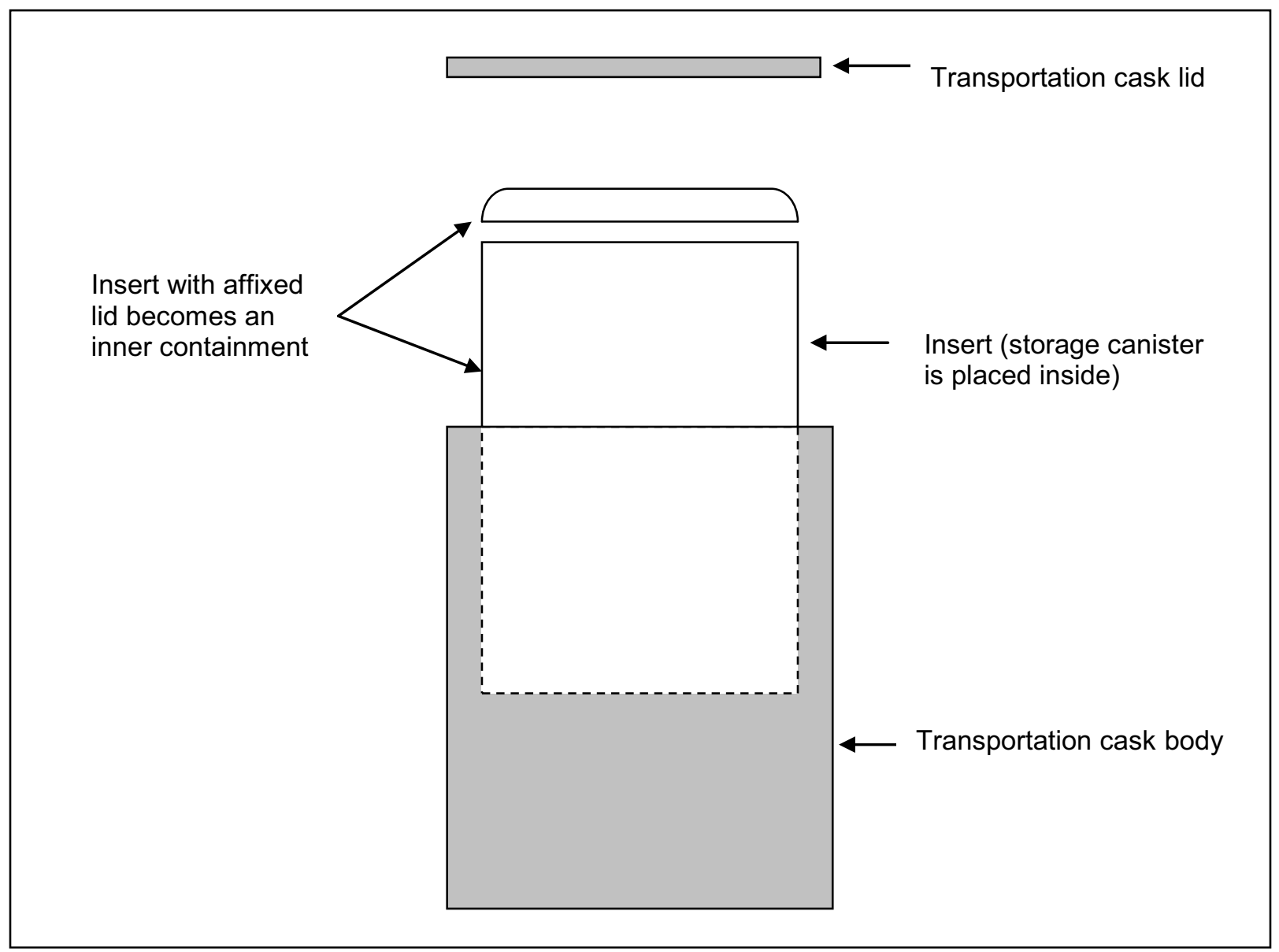

Figure 1. Proposed insert/inner containment concept.

\subsection{Advantages of an Insert/Inner Containment}

The insert/inner containment concept supports a graded approach that allows the device to achieve the necessary safety objectives as the condition of the used fuel, baskets, poisons, and storage canister are established. In addition, standardization of the transportation packagings and insert/inner containment handling interfaces means that other use facilities such as centralized storage site(s) or final processing or disposal facilities can standardize their handling systems. As time passes, storage systems will likely evolve and the variety of canisters that must be accommodated is likely to increase. Standardization of the transportation cask loading, handling, and unloading processes for these storage canisters offers opportunities to improve quality and increase safety and productivity. If the Department of Energy wants to maximize the benefits of standardization at interim storage and final processing or disposal sites, storage canister geometry limits must also be considered.

The insights listed below provide additional details and considerations when using an insert/inner containment for the transportation of used fuel.

- Various insert/inner containment designs can adapt a single transportation packaging design into a system of custom fit transportation packagings, able to transport many storage canister geometries. Future storage canister designs can also be accommodated if size limitations are established.

- The insert/inner containment is less expensive to construct than a transportation cask and can be designed to be reusable. 
- Since it is a separate and distinct component, a potential breach caused by crack propagation through the transportation containment wall due to direct impact or other significant loadings will not affect the insert/inner containment.

- DOE has more than just commercial used fuel to consider in their overall approach to used fuel disposition. DOE has responsibility for a significant amount of DOE-owned used fuel and radioactive waste (vitrified or calcined) that has been or will be canistered. Various insert/inner containment designs can also be fabricated to accommodate differing DOE canister geometries.

- The insert/inner containment can be designed to better protect the storage canister and reduce impact loads on the used fuel, baskets, poisons, and storage canister by minimizing potential gaps within the transportation packaging (i.e., reduce rattling) and/or absorbing impact energy through insert/inner containment material deformation. Many design options are possible, including the use of internal impact limiters, fin or ribbed supports designed to effectively absorb impact energy, etc.

- The insert/inner containment provides an inspectable component that can be leak tested immediately prior to shipment to increase assurances against the release of radiological materials and the intrusion of moderator.

- The insert/inner containment would be new material, not suffering the potentially adverse aging consequences of storage. Its use reduces or eliminates the potential need to inspect, examine, or test the aged storage canisters. Costs and personnel radiation exposures associated with these inspections or examinations may be significantly reduced.

- The insert/inner containment can provide additional benefit by increasing operational safety and cost efficiency as a result of loading and unloading with standardized rigging, which can be incorporated into the walls of the shell or into the lid (requiring the lid to be affixed for lifting purposes if so designed). Standardized rigging can be a significant benefit considering the large number of different storage sites, different storage canister designs, and the potential variety of capabilities at the future transportation destinations. Procedural consistency also increases cost effectiveness. Receiving sites may benefit more because shipping facilities must still handle the storage canisters in preparation for transportation but advantages still exist.

- Using multiple inserts/inner containments could also allow flexibility in the scheduling use of the transportation packaging by implementing staging processes to reduce turnaround time. On the front end, the storage canister can be preloaded into the insert/inner containment and be approved for shipment while waiting for transportation packaging arrival. On the back end, once the insert/inner containment is unloaded with standardized rigging, the transportation packaging can begin a return trip while transfer movements, receiving inspections, testing, and storage canister unloading efforts from the insert/inner containment proceed.

- The insert/inner containment could serve as an unshielded enclosure to facilitate safe handling of significantly degraded storage canisters. Shielding can be provided separately if needed for temporary storage.

\subsection{Other Transportation Considerations}

There are three associated issues that need to be recognized for a more complete understanding of current and future transportation efforts.

\subsubsection{Maintaining Current Practices}

The use of an insert/inner containment is not intended to be a substitute for the efforts currently taken to properly care for and handle used fuel during storage. Current storage practices (e.g., using an inert atmosphere, leak testing to demonstrate the containment integrity, using durable containment, basket, or poison materials, etc.) have been established to minimize or prevent degradation of used fuel, poisons, 
baskets, and the storage canister material and to provide proper safety margins during storage and other post-storage handling and transportation efforts. These practices must continue.

\subsubsection{ASME BPV Code Support}

The American Society of Mechanical Engineers (ASME) Boiler and Pressure Vessel (BPV) Code has established construction rules for transportation and storage containments under Section III, Division 3 (Reference 18). Although the NRC does not endorse Division 3 at this time, it is currently being reviewed in detail by the NRC after recent rewriting efforts. The end goal of this detailed review effort is for the NRC to endorse Division 3. NRC endorsement of Division 3 could change certain aspects of how storage and transportation containments are constructed, such as the use of authorized nuclear inspectors and Code stamping of components.

The ASME committee responsible for Division 3 (Subgroup on Containment Systems for Spent Fuel and High-Level Waste Transport Packagings) is currently gaining approval of construction rules for internal support structures (also known as baskets). Identified as Subsection WD, these rules cover the requirements for strength integrity of items, the failure or excessive deformation of which would cause loss of geometric configuration of the containment contents. Geometric configuration is defined as maintaining geometry of the contents as required by the Design Specification to maintain the relative physical location of the contents (e.g., criticality control and/or damage from physical contact). These rules would apply to internal support structures. These rules would not be applicable to the design of an insert/inner containment since the transportation containment rules located in Subsection WB would need to be satisfied.

The ASME committee responsible for developing Division 3 design rules (Working Group on Design of Division 3 Containments) has recognized the need for improved rules that better address energylimited events such as accidental drops or missile impacts. This committee is developing strain criteria for both storage and transportation containments. This is believed to be a significant step forward in more accurately evaluating the acceptability of these dynamic loadings on containments. The NRC has indicated support for this effort. Assuming that these strain criteria are adopted by ASME as currently written, the insert/inner containment would be able to utilize the strain criteria, yielding a more efficient design.

\subsubsection{Maximum Design Size Envelopes}

There is an increasing demand on commercial utilities to reduce operating costs, including used fuel storage operations. One way to increase cost efficiency is to place more used fuel into storage canisters. The storage canister diameter impacts the geometric envelop available for an additional insert/inner containment inside of the transportation cask. Used fuel after extended storage will be cooler and emit less radiation, reducing the need for shielding and significant heat transfer features in transportation casks. Impact limiter performance can also be revisited to assess potential dimension reduction. These potential dimensional reductions can make placement of the insert/inner containment easier to achieve if needed. To help ensure that used fuel storage canisters remain compatible with future transportation objectives, it is recommended that a consensus be reached between the commercial nuclear industry and the Department of Energy on appropriate size limits. This effort would enhance standardization goals for future transportation packaging designs as well as establish geometry limits for storage canister designs.

\section{RECOMMENDED FUTURE TASK ACTIVITIES}

The following are recommendations that support the continued advancement of the concept proposed in this report. 


\subsection{Addressing Regulatory Issues}

1. Interact with NRC staff regarding the use of a watertight inner component (non-degraded storage canister or inner containment) to achieve moderator exclusion as part of their on-going Regulatory Program Review for Extended Storage and Transportation efforts. In addition, interact with other transportation industry personnel through appropriate meetings or conferences to present this proposed concept and encourage technical debate. The development of a supporting white paper is also recommended.

\subsection{Addressing Technical Issues}

1. Develop a used fuel transportation database (or add to an existing FCRD transportation database) in order to capture pertinent information necessary to support this proposed concept. This effort can help define necessary design input requirements as well as help establish dimensional limits. Specific data could include:

a. specific payload cavity dimensions and weight limits of existing transportation packagings or existing transportation packaging designs.

b. specific dimensions and weights of existing dry storage canisters in use by the commercial used fuel vendors.

c. specific dimensions and weights of DOE-owned used fuel and radioactive waste canisters.

d. confirmation of published transportation dimensional limits to quantify any existing margins.

2. Continue material strain rate research initiated by the NSNFP (Reference 20), seeking higher strain rate responses at the same range of temperatures for the same materials. This research supports improved inelastic structural evaluations for transportation loadings such as accidental drops and impacts

3. Complete a full-scale or reduced-scale drop testing program that demonstrates the viability of the proposed concept and achieves the following two goals:

a. demonstrate the actual structural performance of a representative insert/inner containment (large shell diameter/thin wall ratio) within a representative transportation packaging, including pre- and post-helium leak testing of the inner containment to quantify the watertight function capability.

b. compare actual test deformations of a representative inner containment (from above) with inelastic analysis predictions with the goal of confirming the software prediction capability of structural responses of thin shell components during hypothetical accidental drop events (see Part II, Section 11.3.1 of Reference 19 for similar efforts on stiff components).

4. Interact with other FCRD activities in order to assure a viable exchange of ideas, research proposals, and alternative approaches. The goal is not necessarily to solve the details at this early stage but to engage in discussions that can promote information exchange as well as refine concepts.

a. Before Transportation - need to interface with FCRD storage personnel to assess the anticipated condition of storage canisters and/or the contents (used fuel, baskets, and poisons). Need to agree on when storage activities stop and transportation activities begin for proper coverage.

b. After Transportation - need to understand not only where the used fuel is being transported to (transportation logistics) but also what type of facility (treatment versus disposal) and associated capabilities would exist so that unloading activities can be properly considered (ability to unload transportation packaging and the proposed insert/inner containment, standardized rigging, etc.).

5. Develop alternate handling techniques that can reduce lift heights and/or significantly reduce risks associated with handling canisters when outside the transportation cask. The could be especially useful for storage canisters that have degraded lifting attachments. The following bullets capture 
some initial thoughts and optional approaches that could lead to a loading or unloading process that is safer and easier to implement.

- Can hydraulic devices be used to load and unload containers in a lower horizontal position?

- Can rollers or low coefficient of friction materials be used?

- Can transportation casks with both ends open (bolted closures at both ends) be utilized for loading or unloading in special circumstances?

- For loading purposes, can inverted transportation casks or inserts/inner containments be lowered onto storage canisters resting on special platforms that provide temporary closure while the transportation cask or insert/inner containment is turned right side up? (Reverse process for unloading.)

- Can an entire storage canister be grappled to avoid using degraded lifting attachments?

\section{CONCLUSIONS}

Current storage practices (e.g., use of an inert gas atmosphere, leak testing to demonstrate the containment integrity, use of poisons, use of durable materials, etc.) must continue in order to minimize the potential degradation of used fuel and maintain conditions favorable to future transportation. Nonetheless, for transportation after extended storage, it is prudent to develop a plan that does not rely solely upon successful prediction of material performance and control of material degradation. Although a scientific understanding of the various potential degradation processes is necessary for prevention and mitigation purposes, reliance solely on maintenance of material properties for criticality safety may not be achievable, may not be verifiable with sufficient certainty, or may not be effective.

However, achieving moderator exclusion by utilizing a watertight inner component excludes the possibility of criticality of commercial used fuels during transportation. When the storage canister cannot provide that watertight function, a separate inner containment can provide the watertight function. Following this graded approach, the concept proposed herein provides a positive path forward for DOE to transport used fuel after extended storage, regardless of the condition of the fuel, baskets, poisons, or the storage canister. An updated probabilistic risk assessment that reflects the existence of the watertight inner component would provide additional technical justification. This concept can also support standardization of transportation in a number of areas that can increase the overall effectiveness, cost efficiency, and safety of a transportation effort. Recommendations for further work that continue to support the advancement of this concept are provided in Section 5.

The NRC staff has recently submitted a plan to the Commission that will update the waste confidence decision and enhance the technical and regulatory basis of the existing framework for extended storage periods (Reference 21). This NRC plan considers a timeframe in excess of 120 years to be appropriate for characterization and prediction of aging effects and management issues for extended storage and transportation. This regulatory review provides a unique opportunity to engage the NRC staff in discussions that address how the regulatory requirements may be revised in light of new design approaches, updated probabilistic risk assessments, and additional transportation barriers.

\section{REFERENCES}

1. Department of Energy, "Department of Energy FY 2012 Congressional Budget Request - Nuclear Energy, Defense Nuclear Waste Disposal, Nuclear Waste Disposal," Volume 7, pp 79-80, February 2011.

2. U.S. Code of Federal Regulations, Title 10, Part 51, "Environmental Protection Regulations for Domestic Licensing and Related Regulatory Functions," June 17, 2011. 
3. Transportation and Storage Subcommittee to the Blue Ribbon Commission on America's Nuclear Future (BRC), "Transportation and Storage Subcommittee Report to the Full Commission," Draft, May 31, 2011.

4. U.S. Code of Federal Regulations, Title 10, Part 71, "Packaging and Transportation of Radioactive Material," June 17, 2011.

5. U.S. Nuclear Regulatory Commission, "Moderator Exclusion under Hypothetical Accident Conditions and Demonstrating Subcriticality of Spent Fuel under the Requirements of 10 CFR 71.55(e)," Division of Spent Fuel Storage and Transportation Interim Staff Guidance - 19, Rev. 0, May 2, 2003.

6. U.S. Nuclear Regulatory Commission, Policy Issue Notation Vote, "Moderator Exclusion in Transportation Packages," SECY-07-0185, October 22, 2007.

7. Electric Power Research Institute, "Transportation of Commercial Spent Nuclear Fuel: Regulatory Issues Resolution,” 1016637, Palo Alto, CA, 2010.

8. U.S. Code of Federal Regulations, Title 10, Part 72, "Licensing Requirements for the Independent Storage of Spent Nuclear Fuel, High-Level Radioactive Waste, and Reactor-Related Greater than Class C Waste," June 17, 2011.

9. American Nuclear Society, "Nuclear Criticality Safety in Operations with Fissionable Material Outside Reactors," ANSI/ANS-8.1, Table 3, page 6, 1998.

10. American National Standards Institute, "American National Standard for Radioactive Materials Leakage Tests on Packages for Shipment”, ANSI N14.5, 1997.

11. U.S. Nuclear Regulatory Commission, Advisory Committee on Nuclear Waste, "Use of Credit for Moderator Exclusion in the Licensing of Spent Nuclear Fuel Transportation Packages," ACNWR0260, April 23, 2007.

12. U.S. Nuclear Regulatory Commission, Commission Voting Record on SECY-07-0185, "Moderator Exclusion in Transportation Packages," December 18, 2007.

13. U.S. Nuclear Regulatory Commission, "Safety Evaluation Report - Model No. HI-STAR 180 Package, Certificate of Compliance No. 9325, Revision 0”, Docket No. 71-9325, October 1, 2009.

14. International Atomic Energy Agency, "Regulations for the Safe Transport of Radioactive Material," IAEA Safety Standards Series No. TS-R-1, Paragraph 677, 2009 Edition.

15. L. E. Fischer, et al., Shipping Container Response to Severe Highway and Railway Accident Conditions," NUREG/CR-4829, Lawrence Livermore National Laboratory, Livermore, CA, February 1987.

16. J. L. Sprung, et al., "Reexamination of Spent Fuel Shipment Risk Estimates," NUREG/CR-6672, Sandia National Laboratories, Albuquerque, NM, March 2000.

17. Electric Power Research Institute, "Criticality Risks During Transportation of Spent Nuclear Fuel: Revision 1," 1016635, Palo Alto, CA, 2008.

18. American Society of Mechanical Engineers, "Boiler and Pressure Vessel Code," Section III, Division 3, Containments for Transportation and Storage of Spent Nuclear Fuel and High Level Radioactive Material and Waste, Subsection WB, 2010 Edition.

19. D. K. Morton and S. D. Snow, “Drop Testing Representative Multi-Canister Overpacks,” EDFNSNF-047, Revision 0, January 28, 2005.

20. D. K. Morton and R. K. Blandford, "Impact Tensile Testing of Stainless Steels at Various Temperatures," EDF-NSNF-082, Revision 0, March 31, 2008. 
21. U.S. Nuclear Regulatory Commission, Policy Issue Information, "Plan for the Long-Term Update to the Waste Confidence Rule and Integration with the Extended Storage and Transportation Initiative," SECY-11-0029, February 28, 2011. 